\section{Response to: 'Evidence for treating rheumatoid arthritis to target: results of a systematic literature search update' by Goswami et al}

We thank the authors of the letter ${ }^{1}$ for their comments on our systematic literature review $(\mathrm{SLR})^{2}$ that aimed to compare a target-oriented approach with routine management in the treatment of rheumatoid arthritis to allow an update of the treat-to-target (T2T) recommendations. ${ }^{3}$ In addition to clinical, functional and structural changes as endpoints, comorbidities, cardiovascular risk, work productivity and education as well as patient self-assessment were investigated as outcomes in our SLR. Furthermore, our SLR aimed to update the literature review conducted by Schoels et al, ${ }^{4}$ which was performed in 2009. Therefore, we included studies published from 2009 to 2014.

We did not explicitly look into cost-effectiveness of biologic disease modifying antirheumatic drugs. The T2T activity is generic in nature. Therefore, it does not relate to any particular drug or class of therapies and thus also not to costs. T2T can and, in our view, should be implemented irrespective of the accessibility of certain agents. It should be borne in mind, that using a T2T strategy one can see very similar results with methotrexate (MTX) plus glucocorticoids as can be seen with a biological plus glucocorticoids. ${ }^{5}$ Also, reinstitution of a disease modifying antirheumatic drug that has failed may, at times, be successful because the modalities of application or the responsiveness of a given patient may have changed. ${ }^{6}$

The application of specific drugs and/or their sequence is a topic for management recommendations, as has already been done by European League Against Rheumatism (EULAR), ${ }^{7}$ and is not addressed by the T2T task force. Rather, the focus of our updated literature search was to describe the results of studies that addressed specific populations and endpoints, such as comorbidities, cardiovascular risk, work productivity, education and self-assessment, or patients with long-standing disease. To this end, it was important to decide, when a strategy aiming at a specific target is useful and recommendable and when it may have limitations. We believe that the updated version of the recommendations provides this information.

We agree with the authors of the letter ${ }^{1}$ that it would be an important topic for further research to investigate costeffectiveness in different regions of the world and also to take into account factors specific to certain countries/regions. Indeed, an approach to define environmental factors relevant to different regions of the world has been provided by the WHO in the International Classification of Functioning, Disability and Health. ${ }^{8}$ We also agree that national and international organisations should engage themselves with these topics in health services research. However, this is beyond the scope of the generic question addressed in our activity, namely if T2T is useful and where it may have its limitations. Of note, in many discussions, the aspect of costs is used to defend why T2T cannot be implemented in certain regions or countries, and this is exactly what is contrary to the intention of the recommendations and the search underlying them. T2T can be implemented everywhere and used in accordance with the possibilities available locally at any point in time for the benefit of the patients. Adhering to T2T will always improve the patients' outcome, even if the target may not be achievable in all of them.

Tanja Stamm, ${ }^{1,2}$ Michaela Stoffer, ${ }^{1,2}$ Josef Smolen ${ }^{2,3}$

${ }^{1}$ Section for Outcomes Research, Center for Medical Statistics, Informatics, and Intelligent Systems, Medical University of Vienna, Vienna, Austria

${ }^{2}$ Division of Rheumatology, Department of Medicine 3, Medical University of Vienna, Vienna, Austria

${ }^{3}$ Department of Internal Medicine, Centre for Rheumatic Diseases, Hietzing Hospital, Vienna, Austria

Correspondence to Professor Josef Smolen, Division of Rheumatology, Department of Medicine 3, Medical University of Vienna, 1090 Vienna, Austria; josef.smolen@wienkav.at

Contributors MS, JS and TS were involved in the preparation of this response.

Funding Supported by an unrestricted educational grant from AbbVie. AbbVie had no influence on the writing of this respone to the letter by Goswami et al.

Competing interests None declared.

Provenance and peer review Commissioned; internally peer reviewed.

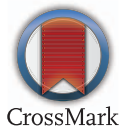

To cite Stamm T, Stoffer M, Smolen J. Ann Rheum Dis 2016;75:e36.

Received 18 March 2016

Accepted 19 March 2016

Published Online First 4 April 2016

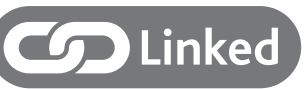

http://dx.doi.org/10.1136/annrheumdis-2015-209094

Ann Rheum Dis 2016;75:e36. doi:10.1136/annrheumdis-2016-209499

\section{REFERENCES}

1 Goswami RP, Basu K, Das S, et al. Evidence for treating rheumatoid arthritis to target: results of a systematic literature search update. Ann Rheum Dis 2016; 75:e35.

2 Stoffer MA, Schoels MM, Smolen JS, et al. Evidence for treating rheumatoid arthritis to target: results of a systematic literature search update. Ann Rheum Dis 2016;75:16-22.

3 Smolen JS, Breedveld FC, Burmester GR, et al. Treating rheumatoid arthritis to target: 2014 update of the recommendations of an international task force. Ann Rheum Dis 2016;75:3-15.

4 Schoels $M$, Knevel R, Aletaha D, et al. Evidence for treating rheumatoid arthritis to target: results of a systematic literature search. Ann Rheum Dis 2010;69:638-43.

5 Nam JL, Villeneuve E, Hensor EM, et al. Remission induction comparing infliximab and high-dose intravenous steroid, followed by treat-to-target: a double-blind, randomised, controlled trial in new-onset, treatment-naive, rheumatoid arthritis (the IDEA study). Ann Rheum Dis 2014;73:75-85.

6 Kapral T, Stamm T, Machold KP, et al. Methotrexate in rheumatoid arthritis is frequently effective, even if re-employed after a previous failure. Arthritis Res Ther 2006:8:R46.

7 Smolen JS, Landewé R, Breedveld FC, et al. EULAR recommendations for the management of rheumatoid arthritis with synthetic and biological disease-modifying antirheumatic drugs: 2013 update. Ann Rheum Dis 2014;73:492-509.

8 WHO. ICF-international classification of functioning, disability and health. Geneva: World Health Organization, 2001. 